\title{
Baseline sensitivity of Brazilian Mycosphaerella fijiensis isolates to protectant and systemic fungicides
}

\author{
Lahyre Izaete Silveira Gomes ${ }^{1}$, Líllian B. J. Bibiano ${ }^{1}$, Gilvan Ferreira da Silva ${ }^{2}$, Rogério Eiji Hanada ${ }^{3} \&$ \\ Eduardo S. G. Mizubuti ${ }^{1}$
}

${ }^{1}$ Departamento de Fitopatologia, Universidade Federal de Viçosa, 36570-000 Viçosa, MG, Brazil; ${ }^{2}$ Embrapa Amazônia Ocidental, 69010-970 Manaus, AM, Brazil; ${ }^{3}$ Instituto Nacional de Pesquisas da Amazônia, 69080-971 Manaus, AM, Brazil

Author for correspondence: Eduardo S. G. Mizubuti, e-mail: mizubuti@ufv.br

\begin{abstract}
Black Sigatoka caused by Mycosphaerella fijiensis is a foliar disease that affects banana plants and large amounts of fungicides are required to prevent crop losses. Intensive applications of single-site fungicides can select for fungicide-resistant isolates. The objective of this study was to assess the sensitivity of 60 isolates of $M$. fijiensis to commonly used fungicides. Using two different protocols, microtiter and Petri plate tests, the effective concentration at which mycelium growth is reduced by $50 \%\left(\mathrm{EC}_{50}\right)$ was determined for thiophanatemethyl, tebuconazole, chlorothalonil and mancozeb. Additionally, partial sequences of the cytochrome b gene were obtained for 46 isolates to detect the G143A mutation, commonly associated with strobilurin resistance. The $\mathrm{EC}_{50}$ values for tebuconazole and thiophanate-methyl

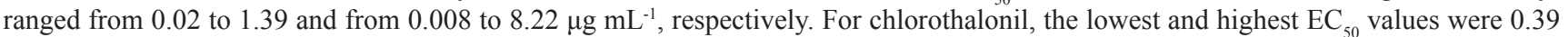
$\mu \mathrm{g} \mathrm{mL} \mathrm{m}^{-1}$ and $53.7 \mu \mathrm{g} \mathrm{mL}^{-1}$, respectively. For mancozeb, approximately $50 \%$ of the isolates had $\mathrm{EC}_{50}$ values greater than $1000 \mu \mathrm{g} \mathrm{mL}^{-1}$. No mutation was found in the isolates assayed for strobilurin resistance. There was no correlation between sensitivity levels to any fungicide and geographic region. Low $\mathrm{EC}_{50}$ values were estimated for most fungicides but, some isolates had high $\mathrm{EC}_{50}$ values for mancozeb. Key words: black leaf streak disease, fungicide resistance, protectant fungicides, strobilurin, tebuconazole, thiophanate-methyl.
\end{abstract}

Black leaf streak disease (BLSD), also known as black Sigatoka, is caused by Mycosphaerella fijiensis M. Morelet (anamorph Pseudocercospora fijiensis M. Morelet) Deighton, an Ascomycete species, and is the most devastating foliar disease of bananas (Marín et al., 2003; Churchill, 2011). Yield losses can be high and disease control depends mainly on the application of systemic and protectant fungicide that are alternated as part of an antiresistance strategy (Marín et al., 2003; Churchill, 2011). Systemic fungicides usually provide better BLSD control than protectant fungicides, but are at a greater risk of control failures due to the development of resistance in the pathogen population (Marín et al., 2003). The main chemical classes of fungicides used to control BLSD are the demethylation inhibitors (DMIs), amines, outer quinone inhibitors (QoI; strobilurins), anilinopyrimidines (APs), benzimidazoles (BCMs), succinate dehydrogenase inhibitors (SDHIs) and guanidines (FRAC, 2010).

Populations of $M$. fijiensis resistant to systemic fungicides are known to occur in several regions. Field isolates of $M$. fijiensis insensitive to benomyl were reported in 1979 (Stover, 1979). Cañas-Gutiérrez et al. (2006) also identified isolates that exhibited high resistance to benomyl. Although benzimidazoles are highly effective on BLSD control, and relatively inexpensive, their use was limited or prohibited in some countries due to the emergence of fungal populations resistant to the fungicides of this group (Marín et al., 2003). Several studies conducted with different fungal species have identified single nucleotide polymorphisms (SNP) associated with resistance to benzimidazoles. For $M$. fijiensis it was demonstrated that a change from cytosine to adenine in codon 198 of the $\beta$-tubulin gene was associated with a change in the phenotype and the mutant isolates acquired medium or high resistance to benomyl (CañasGutiérrez et al., 2006).

Resistance to strobilurin, an outer quinone inhibitor, and sterol demethylation inhibitors are known to occur in several areas. Strobilurin fungicides inhibit the mitochondrial respiration of fungi by binding to the cytochrome bc 1 enzyme complex and several studies have been published reporting resistance to these fungicides (Sierotzki et al., 2000; Chin et al., 2001; Amil et al., 2007). Resistance to strobilurins was found in high levels in populations of $M$. fijiensis in banana plantations from Costa Rica. Approximately $80 \%$ of resistant isolates showed the G143A mutation in the cytochrome b gene, which confers resistance to the fungicide (Amil et al., 2007). The DMI fungicides inhibit the biosynthesis of sterol C-14 $\alpha$-demethylation of 24-methylenedihydrolanosterol, a precursor of the cell membrane component ergosterol in fungi (Brent \& Hollomon, 2007). Resistance to DMIs is also known and resistant isolates of $M$. fijiensis to propiconazole were reported (Romero \& Sutton, 1997).

Given that fungicide resistance in $M$. fijiensis seems to be frequent and ubiquitous, monitoring pathogen 
populations becomes a key component for the management of BLSD. In Brazil, banana crops are spread throughout the country and BLSD is a major problem in many areas, particularly in the Northern region. This study reports the sensitivity of $M$. fijiensis isolates collected across banana production regions of Brazil to commonly used fungicides for BLSD control.

A total of 60 isolates of $M$. fijiensis collected in 2008 and 2009 in banana fields in seven Brazilian states were stored at Embrapa Amazônia Ocidental - CPAA and utilized in this study (Figure 1). The isolates were obtained from leaves with typical symptoms of BLSD randomly collected from symptomatic plants. The isolation was made with a compound microscope and using a sterile fine needle, conidia present on the surface of symptomatic leaves were picked and transferred to PDA medium. The isolates were incubated at $25^{\circ} \mathrm{C}$.

Sensitivity of the isolates were tested for tebuconazole (Folicur 200 CE, Bayer CropScience Ltda), mancozeb (Manzate 800, Du Pont do Brasil S.A.) chlorothalonil (Daconil-BR, Iharabras S.A.) and thiophanate-methyl (Cercobin 700 WP, Iharabras S.A.). The usual methodological procedures for the microtiter plate test recommended by the Fungicide Resistance Action Committee (FRAC) to monitoring populations of Mycosphaerella graminicola, Phytophthora infestans, Fusarium graminearum, Botrytis cinerea, Pyrenophora tritici-repentis and other fungi (FRAC, 2012) to assess the sensitivity to tebuconazole and thiophanate-methyl were modified to use fragmented mycelia instead of spore suspension. A total of 45 isolates assayed for these two fungicides were grown in the M4 liquid medium (Junqueira et al., 1984) for 10 days in a rotary shaker at $25^{\circ} \mathrm{C}$ and 120 $\mathrm{rpm}$. A portion of $0.35 \mathrm{~g}$ of the fresh mycelium mass was transferred to $10 \mathrm{~mL}$ of $2 \mathrm{X}$ potato dextrose (PD) liquid medium and the Politron ${ }^{\circledR}$ apparatus was used to grind the mycelial mass (set a speed 4 for $1 \mathrm{~min}$ ) and to obtain an uniform suspension of hyphal fragments. Fifty microliters of the mycelium suspension was transferred to wells of sterile microtitre plates (ELISA) and mixed with $50 \mu \mathrm{L}$ of PD amended with fungicides at different concentrations. Tebuconazole was dissolved in dimethyl sulfoxide (DMSO) and mixed with PD as to achieve the final concentrations of the active ingredient (a.i.): $0 ; 0.01 ; 0.10 ; 1.0 ; 10$; and 100 $\mu \mathrm{g} \mathrm{mL} \mathrm{mL}^{-1}$. Thiophanate-methyl was dissolved in acetone to the following final concentrations, $0 ; 0.1 ; 1.0 ; 10.0 ; 100$;

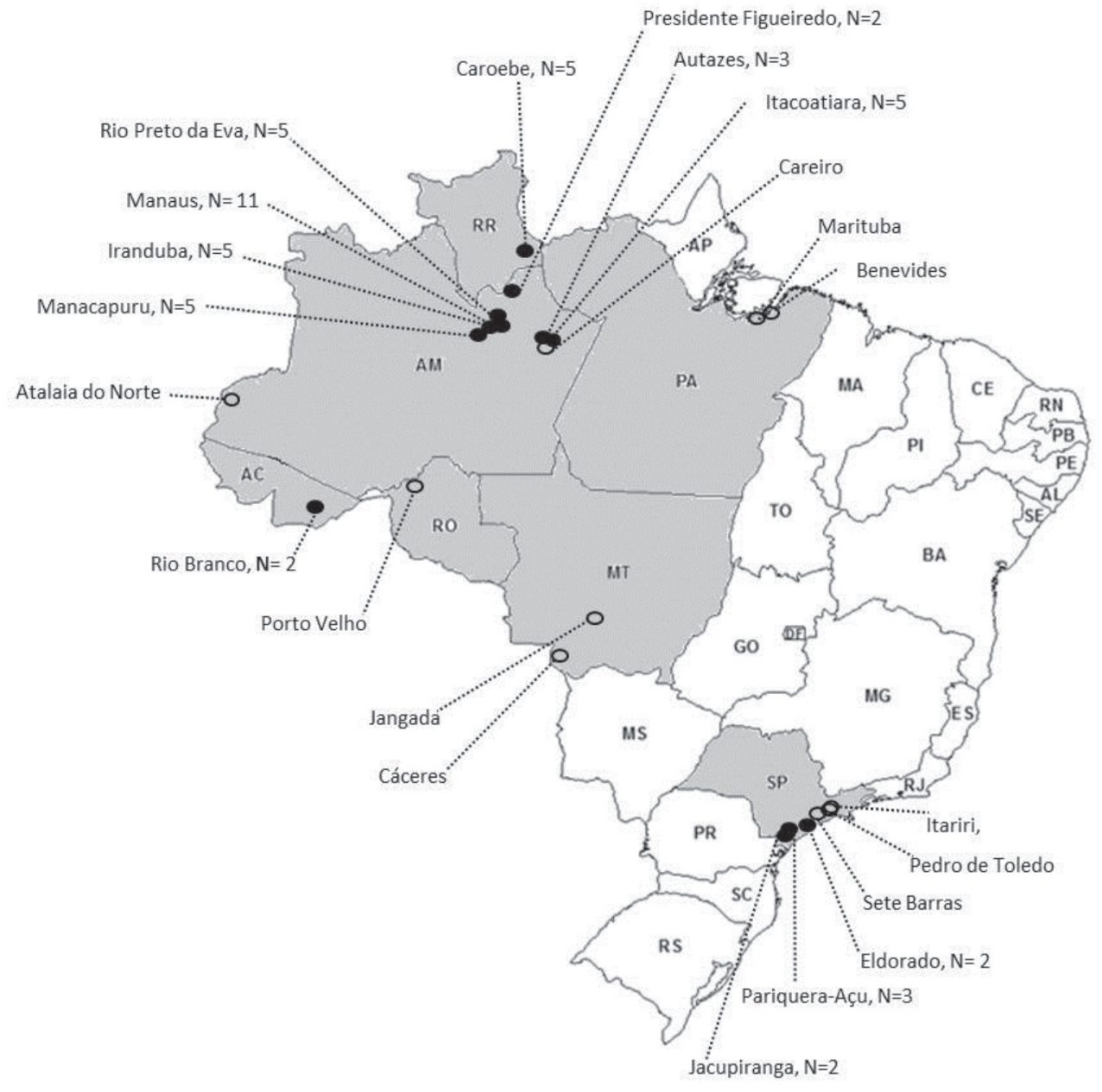

FIGURE 1 - Map of Brazil showing the different states (in gray) and number of isolates collected. Empty circle $\mathrm{N}=1$ and full circle $\mathrm{N}>1$. 
and 1000 a.i $\mu \mathrm{g} \mathrm{mL}{ }^{-1}$. PD with DMSO (1\%) or acetone $(1 \%)$ were used as controls.

Plates were sealed using PVC film to prevent evaporation and contamination, and incubated for 7 days at $25^{\circ} \mathrm{C}$ and $12 \mathrm{~h}$ photoperiod. After incubation, fungal growth was estimated based on mycelium density measured indirectly using a microtiter plate reader at $450 \mathrm{\eta m}$ (Thermo Scientific). Two readings were carried out to assess fungal mass, before and after the 7-day incubation period and the first reading was subtracted from the second to estimate mycelial growth.

The sensitivity of 41 and 48 isolates to the protectant fungicides chlorothalonil and mancozeb, respectively, was assessed based on the radial growth on culture medium amended with fungicides. The isolates were grown in V8 agar medium for 15 days at $25^{\circ} \mathrm{C}$. Four-mm diameter V8 plugs containing growing mycelium of each isolate were excised from colonies and placed upside down in the center of PDA plates amended with different concentrations of fungicides as formulated commercial products dissolved in $1 \%$ dimethyl sulfoxide (DMSO). The final concentrations of the fungicides in the medium were $0 ; 0.1 ; 1 ; 10 ; 100$; $1000 \mu \mathrm{g}$ a.i.mL $\mathrm{mL}^{-1}$. The control was amended with DMSO (1\%) without fungicide. After 15 days of incubation at $25^{\circ} \mathrm{C}$, radial mycelial growth of each culture was measured using a ruler in two perpendicular directions and the original plug diameter was subtracted.

The occurrence of the point mutation G143A in the cytochrome $b$ gene was assayed in 46 isolates using the primers MFcytFor 1 5'CTCAATACTGCCTCAGC-3', MFcytRev_1 (R1) 5'-CCGTAATGTGGTTCATC-3' and MFcytRev_S 5' GTTATAACTGTAGCTCC3' (Garcia, 2009). The DNA of each isolate was extracted using a CTAB method as described by Doyle \& Doyle (1990). Each PCR reaction was performed in $20 \mu \mathrm{L}$ total volume, containing $20 \eta \mathrm{g}$ of template genomic DNA, $2 \mathrm{mM} \mathrm{MgCl}$, $600 \mu \mathrm{M}$ dNTPs, $5 \mu \mathrm{M}$ each primer and $0.4 \mathrm{U}$ of TaqDNA polymerase (Fermentas). PCR was performed in a thermocycler (PTC-100) with an initial denaturation of $94^{\circ} \mathrm{C}(2 \mathrm{~min}), 40$ cycles of $94^{\circ} \mathrm{C}(60 \mathrm{~s}), 70^{\circ} \mathrm{C}(30 \mathrm{~s})$ and $72^{\circ} \mathrm{C}$ (60s), and final elongation at $72^{\circ} \mathrm{C}(10 \mathrm{~min})$. Five microliters of each PCR product was subjected to electrophoresis in $2.0 \%$ agarose gel in $1 \mathrm{x}$ TBE and viewed under UV on gel stained with GelRed (Biotium). Fragments were compared with a 100bp DNA ladder and scored.

Experiments of mycelial growth were set in a completely randomized design with 5 replicates (plates) for each isolate-fungicide concentration combination. For tebuconazole and thiophanate-methyl the effective concentration at which $50 \%$ of mycelial growth was inhibited compared to the no-fungicide control $\left(\mathrm{EC}_{50}\right)$ was determined using linear regression of absorbance reads as a function of the logarithmic-transformed fungicide concentration. This experiment was repeated three times in time. The results had similar trend and data from the third experiment are presented here.
For chlorothalonil and mancozeb, the $\mathrm{EC}_{50}$ was determined using linear regression analysis of the relative growth reduction on the log-transformed fungicide concentration. A distance matrix of geographic location of the isolates was generated using Euclidean distance. Likewise, a distance matrix of the values of $\mathrm{EC}_{50}$ was also constructed. The Mantel test was used to assess the correlation between the two matrices. All statistical analyses were conducted with the R software (R Development Core Team 2008).

For tebuconazole only $13 \%$ of the isolates had $\mathrm{EC}_{50}$ greater than $1 \mu \mathrm{g} \mathrm{mL}^{-1}$. For thiophanate-methyl most isolates (57.8\%) had $\mathrm{EC}_{50}$ lower than $0.1 \mu \mathrm{g} \mathrm{mL}^{-1}, 28.9 \%$ of isolates had $\mathrm{EC}_{50}$ values between 1 and $10 \mu \mathrm{g} \mathrm{mL}^{-1}$ and for $13.3 \%$ of the isolates the $\mathrm{EC}_{50}$ values were greater than $1 \mu \mathrm{g} \mathrm{mL}^{-1}$ (Figure 2).

The $\mathrm{EC}_{50}$ values for tebuconazole and thiophanatemethyl were based on mycelium growth in microtiter plate test because of the difficulties in obtaining conidia from colonies of $M$. fijiensis grown on artificial culture medium prevented us from using spore suspensions. There are different methods to assess the $\mathrm{EC}_{50}$ values (Förster et al., 2004), one commonly adopted is the spiral gradient endpoint. This method can be adapted to assess either the inhibition of mycelial growth or conidial germination. The method used in the present study was time-effective and may be more suited for large-scale monitoring of fungicide resistance. One of the drawbacks, however, is that this method requires extra care to avoid contamination.

The lack of baseline sensitivity information for Brazilian isolates of $M$. fijiensis to the fungicides used in this study limits our ability to properly infer the existence and magnitude of potential shifts in fungicide sensitivity. However, there were differences in the sensitivity of $M$. fijiensis isolates regarding the site-specific fungicides. The mean $\mathrm{EC}_{50}$ value for tebuconazole $\left(0.36 \mu \mathrm{g} \mathrm{mL}^{-1}\right)$ was lower than the mean determined for isolates of M. fijiensis collected in the Ivory Coast $\left(0.73 \mu \mathrm{g} \mathrm{mL}^{-1}\right)$ (Koné et al., 2008). Comparing tebuconazole with other azoles routinely applied to control BLSD, the average $\mathrm{EC}_{50}$ found in this study was higher than that found in a population of $M$. fijiensis in Costa Rica (0.06 $\left.\mu \mathrm{g} \mathrm{mL}^{-1}\right)$ (Romero \& Sutton, 1997). However, differences in methodological procedures do not allow for direct comparisons. Nevertheles, as resistance to DMI-based fungicides is commonly reported (Knight et al, 2002, Stergiopoulos et al., 2003), monitoring programs for DMI resistance should be conducted on a regular basis in Brazil.

Resistance to thiophanate-methyl has been reported for a number of foliar fungal plant pathogens (Luo et al., 2007; Koch et al., 2009; May-De Mio et al., 2011). However, all $M$. fijiensis isolates tested in this study were sensitive to this fungicide. Even though thiophanate-methyl is not registered to control BLSD in Brazil, it is used for the control of the Yellow Sigatoka, and where these two diseases co-occur, resistant isolates of M. fijiensis could 


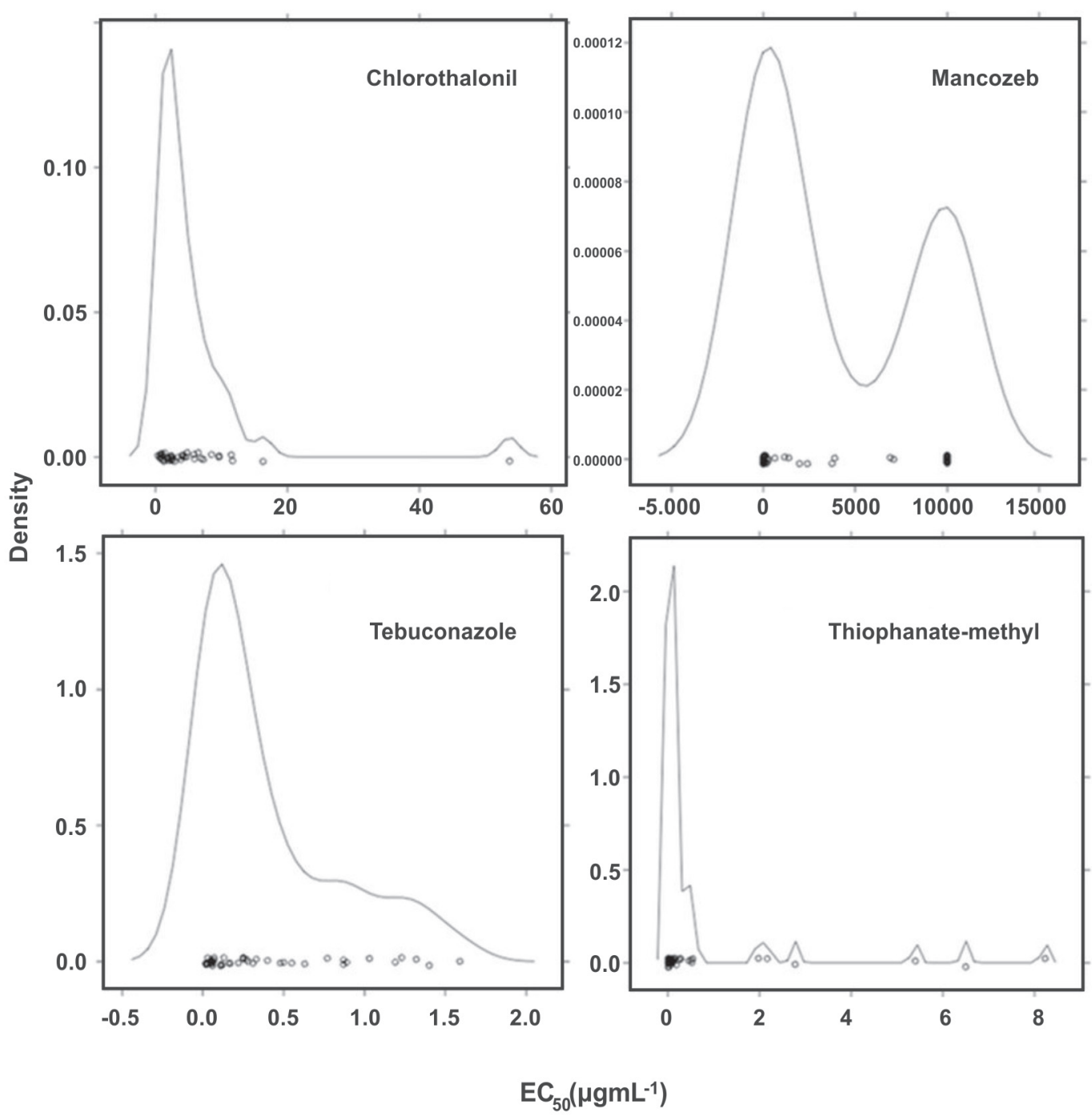

FIGURE 2 - Density frequency of the $\mathrm{EC}_{50}$ values of isolates of Mycosphaerella fijiensis estimated for protectant, chlorothalonil and mancozeb, and site-specific, tebuconazole and thiophanate-methyl, fungicides. The $\mathrm{EC}_{50}$ values $\left(\mu \mathrm{g} \mathrm{mL}^{-1}\right)$ are depicted in the $\mathrm{x}$-axis. The $\mathrm{y}$-axis displays the relative frequency of $\mathrm{EC}_{50}$ values. Each circle represents the average $\mathrm{EC}_{50}$ value for an isolate of $M$. fijiensis.

be selected. Isolates of Monilinia fructicola and Botrytis cinerea were considered sensitive when $\mathrm{EC}_{50}$ values based on mycelial inhibition data were $<1.0 \mu \mathrm{g} \mathrm{mL}^{-1}$ (Yourman et al., 2000; May-De Mio et al., 2011). In the present work, the $\mathrm{EC}_{50}$ values for most isolates were lower than $1.0 \mu \mathrm{g} \mathrm{mL}^{-1}$, therefore they were considered as sensitive.

Of the 41 isolates of $M$. fijiensis tested for chlorathalonil sensitivity, $75.6 \%$ had $\mathrm{EC}_{50}$ values between 1 and $10 \mu \mathrm{g} \mathrm{mL}^{-1}, 14.6 \%$ of isolates had $\mathrm{EC}_{50}$ values less than $1 \mu \mathrm{g} \mathrm{mL}^{-1}$ and $9.8 \%$ of the isolates had $\mathrm{EC}_{50}$ values greater than $10 \mu \mathrm{g} \mathrm{mL}^{-1}$. The mean $\mathrm{EC}_{50}$ was $5.35 \mu \mathrm{g} \mathrm{mL}^{-1}$. The $\mathrm{EC}_{50}$ values for mancozeb had higher range compared with the other fungicides tested. Fifty percent of the isolates had $\mathrm{EC}_{50}$ greater than $1000 \mu \mathrm{g} \mathrm{mL} \mathrm{L}^{-1}$ (Figure 2). Nevertheless, there is no indication of field resistance of $M$. fijiensis to mancozeb, thus there is no evidence of lack of sensitivity to this protectant fungicide. Insensitivity in laboratory studies may not necessarily reflect the potential insensitivity under field conditions because of the extreme selection pressure in amended media compared with the selection pressure under field conditions (Chang et al., 2007). It is likely that the insensitive isolates detected can be insensitive mutants selected in the laboratory that are not representative of the naturally occurring population (Koenraadt et al., 1992; Chang et al., 2007). The resistance to mancozeb probably involves mutations within multiples genes that is associated to a gradual decline in efficacy over time. However, up to date, there is no evidence for the occurrence of such process with mancozeb and the more likely potential resistance mechanism is detoxification of the fungicide (Gullino et al., 2010). In vitro tests using mycelial growth to assess mancozeb sensitivity allowed the detection of insensitive 
TABLE 1 - Sensitivity of isolates of Mycosphaerella fijiensis to the fungicides chlorothalonil, mancozeb, tebuconazole and thiophanatemethyl and the results of the Mantel's test of correlation between geographic distance and mean $\mathrm{EC}_{50}$ values.

\begin{tabular}{lccrrr}
\hline \hline \multirow{2}{*}{ Fungicides } & & & $\mathbf{E C}_{\mathbf{5 0}}{ }^{1}$ values $\left(\boldsymbol{\mu g} \mathbf{~ m L}^{-1}\right)$ & & \multicolumn{2}{c}{$\begin{array}{c}\text { Mantel Test (EC } \\
\text { Geographic distance) }\end{array}$} \\
\cline { 2 - 6 } & $\mathbf{N}^{\mathbf{2}}$ & Minimum & Maximum & Mean \pm SD & r (P value) \\
\hline chlorothalonil & 41 & 0.39 & 53.7 & $5.35 \pm 8.53$ & $-0.02(0.31)$ \\
mancozeb & 48 & 0.09 & $>1000$ & $>1000 \pm 1000$ & $-0.05(0.32)$ \\
tebuconazole & 45 & 0.02 & 1.39 & $0.36 \pm 0.40$ & $-0.11(0.82)$ \\
thiophanate-methyl & 45 & 0.008 & 8.22 & $0.70 \pm 1.74$ & $0.26(0.10)$ \\
\hline
\end{tabular}

${ }^{1} \mathrm{EC}_{50}$ is the effective concentration of the fungicide at which mycelial growth was inhibited by $50 \%$.

${ }^{2} \mathrm{~N}$ is number of isolates tested for each fungicide.

isolates of Ascochyta rabiei, causal agent of ascochyta blight of chickpea (Chang et al., 2007) and Colletotrichum gloeosporioides isolates that causes anthracnose in mango (Kumar et al., 2007). Mancozeb inhibits spore germination (Wicks \& Lee, 1982) and this kind of test needs to be done to collect further information on the sensitivity of $M$. fijiensis to this fungicide.

There was no correlation between $\mathrm{EC}_{50}$ values for all fungicides and geographic regions based on Mantel's test (Table 1), meaning that the isolates were not geographically clustered according to their sensitivity to the fungicides.

The G143A point mutation in the cytochrome $b$ was not found in any of the isolates tested. The amplicon of approximately $200 \mathrm{bp}$ was present in all isolates. However, other point mutations conferring resistance can occur in cyt $b$ gene as the substitution of phenylalanine to leucine at position 129 (F129L) reported in resistant isolates of Alternaria solani (Pasche et al., 2005). Thus, it is possible that point mutations in other positions can occur in M. fijiensis isolates from Brazil and confer resistance to strobilurin.

The Brazilian population of $M$. fijiensis seems to be sensitive at various levels to all tested fungicides. The profile of fungicide sensitivity presented in the present work will allow the appropriate implementation of field monitoring programs to assess the effectiveness of fungicides and to understand the evolution of fungicide resistance in the Brazilian population of M. fijiensis. Because most isolates collected in the state of Amazonas were never exposed to fungicides and no clustering of the sensitivity levels according to geographic region was detected, the $\mathrm{EC}_{50}$ values estimated here may serve as proxy baseline values for future comparison of sensitivity of the population of $M$. fijiensis to fungicides.

\section{ACKNOWLEDGEMENTS}

This work was supported by the Fundação de Amparo à Pesquisa do Estado de Minas Gerais - FAPEMIG. We thank the Coordenação de Aperfeiçoamento de Pessoal de Nível Superior - CAPES and Conselho Nacional de Desenvolvimento Científico e Tecnológico - CNPq for providing fellowships to L. I. S. Gomes.

\section{REFERENCES}

Amil AF, Heaney SP, Stanger C, Shaw MW (2007) Dynamics of QoI sensitivity in Mycosphaerella fijiensis in Costa Rica during 2000 to 2003. Phytopathology 97:1451-1457.

Brent KJ, Hollomon DW (2007) Fungicide resistance in crop pathogens: How can it be managed? $2^{\text {nd }}$ Ed. Brussels, Belgium. Fungicide Resistance Action Committee.

Cañas-Gutiérrez GP, Patiño LF, Rodríguez-Arango E, Arango R (2006) Molecular characterization of benomyl resistant isolates of Mycosphaerella fijiensis, collected in Colombia. Journal of Phytopathology 154:403-409.

Chang KF, Ahmed HU, Hwang SF, Gossen BD, Strelkov SE, Blade SF, Turnbull GD (2007) Sensitivity of field populations of Ascochyta rabiei to chlorothalonil, mancozeb and pyraclostrobin fungicides and effect of strobilurin fungicides on the progress of ascochyta blight of chickpea. Canadian Journal of Plant Science 87:937-944.

Chin KM, Wirz M, Laird D (2001) Sensitivity of Mycosphaerella fijiensis from banana to trifloxystrobin. Plant Disease 85:12641270.

Churchill ACL (2011) Mycosphaerella fijiensis, the black leaf streak pathogen of banana: progress towards understanding pathogen biology and detection, disease development, and the challenges of control. Molecular Plant Pathology 12:307-328.

Doyle JJ, Doyle JL (1990) Isolation of plant DNA from fresh tissue. Focus 12:13-15.

Förster H, Kanetis L, Adaskaveg, JE (2004) Spiral gradient dilution, a rapid method for determining growth responses and $50 \%$ effective concentration values in fungus-fungicide interactions. Phytopathology 94:163-170.

FRAC (2012) FRAC Monitoring Methods Status: January 2012. Available at: http://www.frac.info/frac/index.htm. Accessed on March 21, 2012.

Garcia SAL (2009) Identification, validation and use of ESTderived molecular markers from the genomes of Mycosphaerella fijiensis and Musa spp. M.Sc. Dissertation, Universidade Federal de Lavras. Lavras, MG, Brazil.

Gullino ML, Tinivella F, Garibaldi A, Kemmitt GM, Bacci L, Sheppard B (2010) Mancozeb: Past, present, and future. Plant Disease 94:1076-1087.

Junqueira NTV, Chaves GM, Zambolim L, Romeiro RS, Gasparotto L (1984) Isolamento, cultivo e esporulação de Microcyclus ulei, 
agente etiológico do mal das folhas da seringueira. Revista Ceres 31:322-331.

Knight S, Wirz M, Amil A, Cook A (2002) Fungicide resistance in Mycosphaerella fijiensis Morelet: Current status and outlook. In: XV Reunion Acorbat, Memorias... Medellín, Colombia. Asociacion de Bananeros de Colombia.

Koch PL, Grau CR, Jo Y-K, Jung G (2009) Thiophanate-methyl and propiconazole sensitivity in Sclerotinia homoeocarpa populations from golf courses in Wisconsin and Massachusetts. Plant Disease 93:100-105.

Koenraadt H, Somerville SC, Jones AL (1992) Characterization of mutations in the beta-tubulin gene of benomyl-resistant field strains of Venturia inaequalis and other plant pathogenic fungi. Phytopathology 82:1348-1354.

Koné D, Badou OJ, Bomisso EL, Camara B, Aké S (2008) Activités in vitro de différents fongicides sur la croissance chez Mycosphaerella fijiensis var. difformis Stover et Dickson, Cladosporium musae Morelet et Deightoniella torulosa (Syd.) Ellis, parasites isolés de la phyllosphère des bananiers en Côted'Ivoire. Comptes Rendus Biologies 332:448-455.

Kumar AS, Reddy NPE, Reddy KH, Devi MC (2007) Evaluation of fungicidal resistance among Colletotrichum gloeosporioides isolates causing mango anthracnose in Agri Export Zone (AEZ) of Andhra Pradesh, India. Plant Pathology Bulletin 16:157-160.

Luo Y, Ma Z, Reyes HC, Morgan DP, Michailides TJ (2007) Using real-time PCR to survey frequency of azoxystrobin-resistant allele G143A in Alternaria populations from almond and pistachio orchards in California. Pesticide Biochemistry and Physiology 88:328-336.

Marín DH, Romero RA, Guzmán M, Sutton TB (2003) Black Sigatoka: an increasing threat to banana cultivation. Plant Disease
$87: 208-222$.

May-De Mio LL, Luo Y, Michailides TJ (2011) Sensitivity of Monilinia fructicola from Brazil to tebuconazole, azoxystrobin, and thiophanate-methyl and implications for disease management. Plant Disease 95:821-827.

Pasche JS, Piche LM, Gudmestad NC (2005) Effect of the F129L mutation in Alternaria solani on fungicides affecting mitochondrial respiration. Plant Disease 89:269-278.

R Development Core Team (2008) R: A language and environment for statistical computing. Available at: http://www.R-project.org. Accessed on January 10, 2012.

Romero RA, Sutton TB (1997) Sensitivity of Mycosphaerella fijiensis, causal agent of black Sigatoka of banana, to propiconazole. Phytopathology 87:96-100.

Sierotzki H, Parisi S, Steinfeld U, Tenzer I, Poirey S, Gisi U (2000) Mode of resistance to respiration inhibitors at the cytochrome bc 1 enzyme complex of Mycosphaerella fijiensis field isolates. Pest Management Science 56:833-841.

Stergiopoulos I, Van Nistelrooy JGM, Kema GHJ, De Waard MA (2003) Multiple mechanisms account for variation in base-line sensitivity to azole fungicides in field isolates of Mycosphaerella graminicola. Pest Management Science 59:1333-1343.

Stover RH (1979) Field observations on benomyl tolerance in ascospores of Mycosphaerella fijiensis var. difformis. Transactions of the British Mycological Society 72:518-519.

Wicks T, Lee TC (1982) Evaluation of fungicides applied after infection for control of Plasmopara viticola on grapevine. Plant Disease 66:839-841.

Yourman LF, Jeffers SN, Dean RA (2000) Genetic analysis of isolates of Botrytis cinerea sensitive and resistant to benzimidazole and dicarboximide fungicides. Phytopathology 90:851-859.

TPP-2013-0122

Submitted: 11 July 2013

Revisions requested: 23 September 2013

Accepted: 21 November 2013

Section Editor: Emerson M. Del Ponte 